Association for Information Systems

AIS Electronic Library (AISeL)

Wirtschaftsinformatik 2021 Proceedings

Track 3: Student Track

\title{
Replicating a Digital Transformation Case
}

Sandy Schmidt

Technische Universität Chemnitz

Marius Voß

Technische Universität Chemnitz

Hendrik Wache

Technische Universität Chemnitz

Sarah Hönigsberg

Technische Universität Chemnitz

Barbara Dinter

Technische Universität Chemnitz

Follow this and additional works at: https://aisel.aisnet.org/wi2021

Schmidt, Sandy; Voß, Marius; Wache, Hendrik; Hönigsberg, Sarah; and Dinter, Barbara, "Replicating a Digital Transformation Case" (2021). Wirtschaftsinformatik 2021 Proceedings. 11.

https://aisel.aisnet.org/wi2021/XStudent/Track03/11

This material is brought to you by the Wirtschaftsinformatik at AIS Electronic Library (AISeL). It has been accepted for inclusion in Wirtschaftsinformatik 2021 Proceedings by an authorized administrator of AIS Electronic Library (AISeL). For more information, please contact elibrary@aisnet.org. 


\title{
Replicating a Digital Transformation Case
}

\author{
Sandy Schmidt ${ }^{1}$, Marius Vo $\aleph^{1}$, Hendrik Wache ${ }^{1}$, Sarah Hönigsberg ${ }^{1}$, Barbara Dinter ${ }^{1}$ \\ ${ }^{1}$ Chemnitz University of Technology, Business Information Systems - Business Process and \\ Information Management, Chemnitz, Germany \\ scsaonline@web.de \\ \{marius.voss, hendrik.wache, sarah.hoenigsberg, barbara.dinter\}@wirtschaft.tu-chemnitz.de
}

\begin{abstract}
This study is a methodological replication of the PROFUND method for the implementation of digital transformation projects in small and mediumsized enterprises (SMEs). In the original study, a method for improving the Value Co-Creation (VCC) of an SME network was applied in the digital transformation of a network of textile manufacturers to validate four existing propositions for improving the VCC. This study replicates (1) the procedure in the case study, (2) the guidelines for improving the VCC, and (3) the evaluation of the results via the DART model and transfers them to a network in the metal industry. The method was transferable and the propositions could be reconfirmed. The results of this study confirm the results of the original study and thus validate the procedural structure used there.
\end{abstract}

Keywords: Value Co-Creation, Digital Transformation, Replication.

\section{Introduction}

Companies are currently facing special challenges which are being increased by the digitalization in the society. Small and medium-sized enterprises (SMEs) are particularly affected by this and often face higher hurdles when trying to take part in digital transformation projects in order to keep pace with the digitalization of society $[1,2]$. Particular challenges of SMEs include limited resources (e.g. funds but also staff) $[3,4]$, strong networking with other partner companies (with many dependencies to consider) $[5,6]$ and lack of digitalization skills (e.g. as the owner often holds almost all management functions at once) [1, 7]. The digital transformation can be described as: "a process that aims to improve an entity by triggering significant changes to its properties through combinations of information, computing, communication, and connectivity technologies" [8]. Especially in large companies, DT is a strategically driven issue, with digital business strategies and new roles such as chief digital officers [9-12]. In contrast, "[c]ompared with large firms which have greater resources, SMEs are sometimes struggling with survivals rather than peacefully planning long-term strategies" [13].

The value network of SMEs is becoming increasingly complex as companies specialize in their skills in order to compete globally $[2,3]$. This fragmentation and close interlocking of companies makes transformation processes for SMEs very 
negotiation-intensive [5], as digital solutions inevitably have to be designed across several actors [14]. However, digitalization in the value network offers the opportunity to minimize the differences between customers and partners by closely interconnecting them and promotes value co-creation (VCC) $[12,15,16]$.

The research topic of DT from SMEs has gained importance in recent years, but is still scarcely considered [1, 3, 4], even though over 99\% of European companies are considered SMEs [17]. Furthermore, studies show that digitalization continues to grow significantly in importance for SMEs [18]. However, previous research results are often insufficient for SMEs. For example, a twenty-man company, given the limited resources available, will not be able to afford a chief digital officer, an innovation lab, and often not even an IT department or a strategy development project spanning several years. Furthermore, DT initiatives are often described as strategically planned projects, but in the SME context it is clear that these projects should be planned considering the VCC at a network level [19]. There are still few empirical results available on the topic of DT of VCCs in SME networks. In recent years, there have been repeated calls for empirical studies to investigate the joint value creation and also its digitalization (e.g. via digital platforms) in network settings (several companies working together in a real setting) [20-22]. These studies, especially as long-term studies, offer a deep insight into the interdependencies in the network, but due to their high complexity they are preferably carried out as single embedded case studies [23], which makes these studies vulnerable with regard to their generalizability.

For this reason, this paper examines an SME network and its possibilities for the DT of their VCC, which is designed as a replication of an already published study. Both studies focus on the question of how the network VCC can be improved through the use of digital technologies. Replication research is gaining significance in IS research, because by replicating (i.e. repeating in a modified form) studies, our discipline can increase the rigor of research and thus strive for a higher degree of maturity [24]. In the present paper, therefore, a replication approach is pursued, based on a case study in the textile industry, in order to verify the transferability of the obtained insights to another SME value network in the metal industry. This involves a methodical replication of a case study of [19, 25-27], which applies the same method as the original study in a different context. A positive result, which confirms the findings of the original study, allows the generalization of the original contribution to the new context; if the previous results cannot be replicated, this does not mean that the previous results are 'wrong', but that they cannot be transferred to the new context, which offers further opportunities for further research [24]. The remainder of the paper briefly describes the replicated case after the foundations and research approach, before discussing the case comparison. The paper ends in a conclusion.

\section{Foundations of Digital Transformation and Value Co- Creation}

Digital transformation is a technology-induced change and comprises a goal-oriented transformation in the areas of organization, processes and technologies, which is 
necessary for the success of companies in the digital age [28]. It significantly changes the company's relationships with its key stakeholders such as customers, suppliers or employees $[14,29]$. As part of the digital transformation, information technology and information systems are positioned more visibly in the economy and society [28]. This means that digital technologies are used to have a positive influence on the business [10] and in the process the company is changed from the processes to the organizational structure to the business model. As a demarcation to the IT-enabled transformation, at the end of the digital transformation there is a newly created business identity [30] which can be achieved through innovations in the business model [31]. The focus is not on the effects in the individual company but on the radiation into the value network [8]. Automation plays a central role as an important mechanism of digitalization. Advantages that arise can be seen in increases in turnover or productivity, innovations in value creation and new forms of interaction with customers [10]. In addition to efficiency-enhancing measures such as process digitalization and automation, joint value creation with customers and partners plays a key role in the digital transformation of companies [12, 14, 29]. Furthermore, practical studies show the importance of this topic [18], with 69 percent of the companies surveyed stating that customer communication is the decisive success factor for digitalization.

In the digital era, cooperation includes activities at the relational level to contribute and maintain resources, and actions at the network level to improve resource integration [22]. Companies should initiate an open communication process with their stakeholders and strive for new ways of value creation [15]. For many years now, traditional value creation concepts and conservative patterns of interaction (e.g. mass producing goods or rendering standardized service) have been considered to cause little customer satisfaction and companies are encouraged to strive for co-creation and personalized interaction [32]. Prahalad and Ramaswamy [32] identify Dialogue, Access, RiskBenefits and Transparency, or DART for short, as the basis for VCC interaction. These four prerequisites for interaction are also referred to below as characteristics or building blocks of the VCC. VCC can be seen as a collaborative and dyadic process [33]. It is about jointly identifying and solving problems and not about transferring activities to the customer, as in self-service, or simply satisfying the customer [32, 33]. There is a shift from value-in-exchange to value-in-use and the cognition the beneficiary (e.g. customer) is always involved in the process of value creation [21]. Apart from the dyadic perspective, the VCC can appear as a network phenomenon [22]. Considering the distributed character of the VCC in this case the definition of VCC as the processes and activities of resource integration that involves different actors in the service ecosystem (networked actors) is more appropriate [21].

\section{Research Approach}

\subsection{Case Setting}

The industries in Germany that are still least digitalized include not only healthcare and vehicle construction, but also other manufacturing industries [18]. Therefore, the choice 
of a network from the area of 'manufacturing of metal products' in this case study as a representative of the manufacturing industry is a good example of an area with a high pressure to digitalize. The replicated case is hereafter referred to as the metal case.

Three companies, whose value creation is carried out in a shared value creation network, were investigated for over four months and represent the unit of analysis in the metal case (conducted in a master thesis). The company $\mathrm{C} 1$ has a total of ten employees, eight of whom work in production. Company $\mathrm{C} 2$ is the smallest company with a total of 3.5 employees. Company $\mathrm{C} 3$ can be classified as a small enterprise, with a total of 20 employees. All three companies follow the engineer-to-order approach in their production. The individual products are individually tailored to customer needs and are produced in small quantities [34]. The network relationship is structured as follows: C3 is the supplier of metal parts for both network partners. C2 additionally purchases external edge smoothing services for parts of $\mathrm{C} 1$, which it has had lasered by C3. C3 purchases bending services from $\mathrm{C} 1$ within the scope of a cooperation if it cannot produce the parts itself. Due to this type of production, the setting under consideration represents a process industry, since not discrete units but rather work steps are offered. The network works exclusively in the B2B context. In comparison to this, four textile companies with 12-235 employees over a period of more than three years were considered in the original case, hereinafter referred to as the textile case. Similar to the metal case, the companies act as service providers to each other, from knitters and weavers to finishers and coaters. The technical textile industry is also a process industry. The companies follow an engineer-to-order approach for technical textiles as well. This network also works exclusively in the B2B context.

While the sampling in the textile case is a theoretical sampling along the textile value chain, the metal case is a convenience sample to map a small portfolio section of the focal company where one of the authors is employed [35]. It will be checked whether the results can be transferred to another industry, from textile to metal, with the same setting in terms of engineer-to-order, B2B, SME, and process industry.

\subsection{Procedure for the Replication Study}

According to Niederman \& March [36], "“c]ase studies present a rich and open set of possibilities for replication" and "subsequent case studies can act as a kind of natural replication of the original." In this paper we perform a methodological replication [24] by reusing a procedural structure from a prior case study in a different context. This is intended to validate and generalize the previously obtained findings by confirming them in a different context. Another type of replication is exact replication, where, in addition to the research methodology, the context should also be replicated exactly [24]. In our case this would mean to replicate the case study again in the textile industry with the same contextual parameters. However, this does not correspond with the goal of using the procedural structure of the prior case study for validation and generalization in another context (e.g. the metal industry) and is therefore unsuitable for our purposes. The third type of replication is the contextual replication, which deliberately uses a different methodological approach (for example a quantitative survey) to answer the same research question [24]. Since we believe that our due to the procedural structure 
we want to validate in a network context, that a single embedded case study is the best methodological approach to verify the findings of the original study.

Three aspects of the original study are applied to the new context: (1) the process in the case study, (2) propositions for improving VCC, and (3) evaluation of the results using the DART model. In the textile case, a method for the DT of VCCs in SME networks was derived based on observations of the network over several years. This method specifies (1) the process of the case study. The aim is to check to what extent the method is transferable to another case. It was considered that only suitable sections of the method should be used and that the companies should make their own adaptations and justify them for themselves. The steps are identical, but the instruments such as questionnaires, interviews, etc. were freely chosen within the method in both cases. The sequence and structure of the method steps in this paper are therefore also reflected in the subsections of section 4 The Metal Case.

The process in the case study (1) is structured as follows: In the first step, the common goals and the vision of the network are defined or formulated in interviews and surveys. Subsequently, the VCC process in the network is recorded. The modeling of the VCC process in both cases takes place with the help of the Business Process Model and Notation (BPMN). In both cases, the stages of digitalization were determined by online questionnaires, which were sent out in advance of the interviews. Afterwards the current and desired degree of digitalization was determined in both cases with regard to the modeled process and the resulting phases. Subsequently, recommendations for digitalization were developed with all partners in the network. In the penultimate step of the case study, the actual and desired degree of digitalization was compared in tabular form. In a final online questionnaire and interviews, possible measures were presented and then prioritized. In the last step of the case study, the actual implementation of digitalization measures takes place at the company level. The method used for this phase is primarily prototyping, which is intended to define the requirements of the user and provide him with a preliminary system for test purposes. In the metal case a combination of real life and simulated situation was used, where the simulation prototype with a low design is implemented in real circumstances by a lower manufacturing effort. In the textile case, the IT solutions such as a joined IT platform [27], were fully implemented and transitioned to real operations.

(2) Four propositions to facilitate the network VCC (P1-4) were derived from previous literature, and used as kernel theory for the IT platform development in the textile case [25]. To facilitate the network VCC, (P1) the internal processes should be modular and have defined interfaces, so that the individual process steps of different network actors can be combined at will. To facilitate the network VCC, (P2) all actors involved in the VCC process of the network should be treated as equal participants. To facilitate the network VCC, (P3) efficient and standardized communication for the transfer of information and knowledge should be established between the actors of the network. To facilitate the network VCC, (P4) there should be a cross-organizational IT support for the modular VCC processes in the network, allowing efficient standardized communication between the equal actors of the network. Previous work [25] showed that the propositions were supported by the empirical data collected in the textile case study. The propositions were confirmed according to the case study methodology [37] 
by analytical generalization based on empirical findings as opposed to the inferencebased statistical generalization used in the survey methodology. In the metal case these four propositions were examined again and, in addition, their transferability to a different industrial context was evaluated.

(3) Evaluation of the results via the DART model: In both cases, the DART model of Prahalad and Ramaswamy [32] was used to validate that the DT of the VCC also has a positive effect on the VCC as anticipated. The DART model with its components can be used to check whether a successful VCC has been established, as it describes four basic prerequisites that must be present between co-creating actors. Dialogue refers to the equal two-way interaction between actors, which is supported by Access (to important information), and Transparency (information symmetry between actors). Risk-Benefits additionally addresses the empowerment of actors to assess the risks of interactions in the VCC [32]. The application of the DART model therefore represents the same validation tool for both cases.

\subsection{Data Collection and Analysis for the Metal Case}

For the realization of the presented single embedded case study, (online as well as physical) questionnaires, interviews and observation techniques were used to collect the data, thus enabling triangulation [37]. To this end, data collected using the various techniques were analyzed as part of a data triangulation to determine which findings could be supported by multiple sources of evidence or data collection techniques [37]. In addition to the questionnaires, a short interview was conducted with each of the owners. In particular, the use of open-ended questions was intended to extend the answers given so far to achieve more comprehensive results. In the course of semistructured interviews, questions were asked about the companies' goals and vision, the answers to the online questionnaire, and the degree of digitization in the individual phases of the value creation process.

In addition to documentaries and interviews, observations were made in the metal case. One author is an employee in one of the companies of the network, so that the work process could be recorded through participant observation. Furthermore, the methodology of direct observation was applied, which can be divided into formal (observation of meetings) and informal (during field research) data collection measures [37]. In particular, formal and informal observations were made by inspecting the general premises and shop floors of the companies.

For the data analysis the questionnaires were evaluated. After the evaluation of the first online questionnaire, the companies were sent a document by e-mail in the leadup to the interviews for a final decision on specific topics. The interview could only take place once all three companies had reached agreement. The interviews were evaluated using the qualitative content analysis according to Mayring [38]. For this purpose, the structuring content analysis using the MAXQDA tool was selected. The main categories in the coding were deductively defined by the textile case, but subcategories were freely coded. In the textile case, data from 2017-2020 were collected via interviews, questionnaires, workshops, observations, and document analysis and also evaluated with MAXQDA in a rather abductive procedure [cf. 39]. 


\section{The Metal Case}

\subsection{Goals, Vision and Process}

The goals and visions of the three companies were surveyed with the help of interviews. The clearest and most concise goal to be pursued by the DT initiative was to increase the degree of digitalization and thus optimize processes. In addition, goals were also named which would provide an insight into the work of the other companies and create suggestions for their own work, as well as reveal opportunities to work "hand in hand" or to stimulate cooperation. The vision is defined as the development or introduction of an information system or program that is installed across partners and customers. Each actor can place requests according to his orders and share them with several other actors as well as gain insight into the status of the completion. The goals and visions are formulated considering the value creation process in the network. The development of the comprehensive VCC process in the network was carried out in interviews with the companies, where the companies agreed on the structuring of the process and worked out which interfaces they use between the actors. The inclusion of the already modular value creation process in the observed network and, above all, the definition of the interfaces facilitates joint value creation from the point of view of the companies, since the individual process steps can be combined with the help of defined interfaces between the actors in the network. On this basis the value creation process was divided into the following phases: (1) customer needs, (2) feasibility analysis, (3) network construction and calculation, (4) production and (5) logistics and project end. The interfaces are mostly not fully digital and also not standardized; they range from technical drawings to job tickets to completion notifications. The process was recorded in a detailed BPMN, which was used as a common basis for discussion in the DT initiative. Especially in the production phase it could be observed that the bidirectional exchange with customers and partners only takes place in case of problems. This is completely different in other phases, such as 'customer needs' or 'logistics \& project end', where regular exchange takes place. In the 'feasibility analysis' phase, access to information could be optimized, since relevant information is currently either stored in the head of employees or noted on slips of paper and scattered on computers. Here, the transparency of feasible services to customers and partners could also be improved. In summary, it can be said that companies want to adapt these aspects internally in order to achieve an increase in VCC. The goal in the metal case is to use digitalization as the basis for tight integration in the network, which makes the boundaries between customers and providers dissolve. Due to the lack of hierarchies in the VCC process, all participants are thus on an equal level. In practice, the implementation of this in the metal case was initially rather difficult. Even internally, not all employees are equal, especially in terms of access to information and knowledge, which is also due to the different work areas and departments. Although the companies see the advantage of a higher production capacity utilization here, they always regard the competition as a danger: "[...] if the customer knows everything, exactly how everything is done, then he can also use this knowledge to apply it against the competition again. So, there you have to be careful that this is not counterproductive, the whole story. " In the course of 
the case, however, the idea of an equal exchange platform developed more and more: "Well, the optimum would be if there was a program where all companies had access, both supplier and customer [...]." However, the most important criterion here is controlling the visibility of sensitive information, which shows that trust is a key element for the network VCC in our network. Nevertheless, the dominant impression from the inter-company information exchange in the interviews is that "paper chaos", "knowledge in the head" and "isolated small databases where we have already entered a little bit of information" are predominant. The cross-organizational IT support in the metal case is intended to provide access to resources and focus on continuous information supply and easy knowledge exchange.

\subsection{Digitalization Level, Potentials and Recommendations}

With help of process modeling, the actual degree of digitalization per company for the individual phases of the VCC process in the network was recorded during the interviews. This was considered for customer communication, partner communication and internal communication. In line with the textile case [19, 25-27], the degree of digitalization in the metal case is also differentiated into five levels in order to ensure comparability. In stage one, "Volatile", information is passed on verbally on an ad hoc basis and is not always documented; communication is error-prone and timeconsuming. This stage includes personal conversation, a telephone call or communication via handwritten notes. In stage two "Persistent-Simple" communication takes place via e.g. e-mail, in which the content is stored but not in a structured way. Digitalization in the third stage, "Persistent-Structured", can be described as more efficient, in which templates, such as Word/Excel templates, are already used to structure and, if necessary, standardize the content. If documents are stored and shared in a common repository, as is possible with Dropbox or Google Drive, for example, the fourth stage of digitalization is "Persistent-Structured-Shared". The most efficient and optimized communication takes place in the last stage, the "Persistent-Structured-Shared-Controlled" stage. Here, information systems are used to support the process flow, whereby the structured data is forwarded to the right actor in the process.

In customer communications, the highest level of digitalization was achieved in the "network design \& calculation" phase. The decisive factor here is that digital templates are used to send offers or order confirmations by e-mail. The lowest level of digitalization in all companies is found in the "production" phase. The reason for this is that, especially in the case of problems in production, communication is done by telephone. The same low level of digitalization across all companies in the "logistics and project end" phase is due to customer queries about the delivery status by e-mail or telephone. Partner communication is by far the least digitalized, followed by customer communication. A somewhat more positive picture emerges in the case of companies' internal communication, which is somewhat more digitalized and standardized, see Figure 1. 


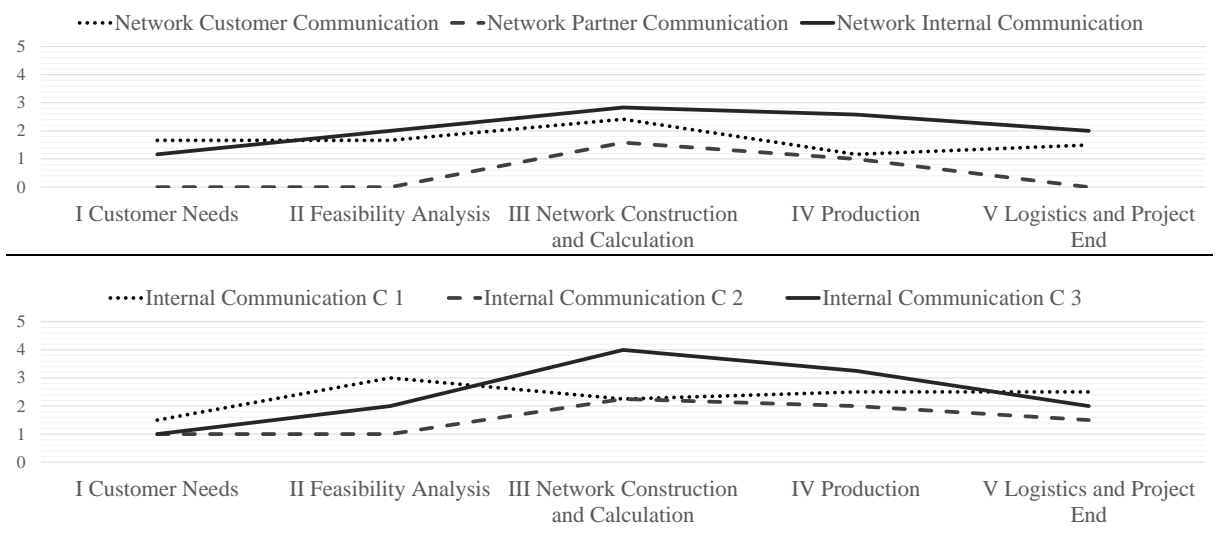

Figure 1. Level of digitalization in the metal case

The internal communication and thus used systems differ more between companies than with the other two communication types. C3 is the most digitalized, which is mainly due to the existing PPS/ERP system, which is used in almost all phases. In the system "all the articles [...] are recorded, are given a unique ID in the system. In there [...] then also the cost centers [...] for processing are titled, yes, and in there all further links are made with our CAD program...". C1 and C2 do not have such a system, only individual databases or Excel lists, calculation programs and digital templates. The companies have been able to identify that this lack of comprehensive IT support hinders the efficient flow of information and knowledge and that there is a need for action here. Overall, the companies have a low level of digitalization. From the sections 4.1 and 4.2 some recommendations and potentials can be derived for the enterprises with the help of the propositions as assistance. A recommendation is based in particular on the consideration that the (P1) VCC process can be broken down into individual steps and that it is important to draw clear boundaries between the actors and to define responsibilities and rights. Furthermore, (P2) equality among the actors represents a facilitation in the process, which in turn would lead to an increase in the VCC. These two points are present, but should be strengthened. In connection with (P3) efficient information and knowledge flow and (P4) comprehensive IT support, a centralized knowledge base, where information is stored and made accessible, would be an important component. IT can take on the role of an initiator, supporter or enabler. The result could be a shared IT platform, which would facilitate the VCC process. It is important to create a comprehensive IT support and not to establish an unmanageable system landscape in the company. Based on these findings, the companies in the metal case then derived individual digitalization measures to achieve improved IT support.

\subsection{Prioritization and Implementation}

A target digitalization level was determined and concrete digitalization proposals were recorded. From the interviews and the questionnaires, all comments on digitalization measures were collected. The differences between the actual and target level of 
digitalization give rise to additional considerations. From the digitalization suggestions that were made, such as an internal messenger, digitalization measures along the VCC process could be worked out together with the actual and the target level of digitalization: "Well, internal communication, there it would be again with the internal messenger, that you could now communicate order-accompanying special features internally or if the customer actually calls, what does it look like? That you could also prioritize this internally, for example, again”.

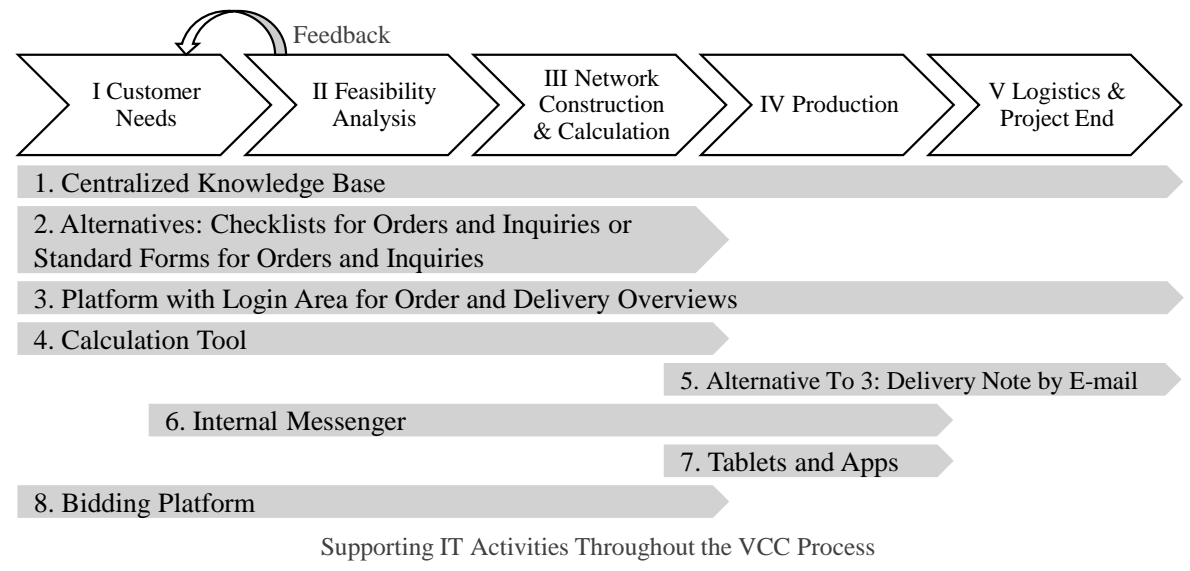

Figure 2. Digitalization initiatives in the metal case

After the development of nine measures, these were evaluated by means of an online survey and presented to the companies with examples. The actual suitability for implementation in the company was specifically asked, but always with regard to the individual communication types. They were able to choose between "suitable", "not suitable" or "not specified". Figure 2 shows the respective measures, evaluated by the companies according to their importance. Seven of the nine measures are applied in the first three phases, with measure three and five representing alternatives to each other. The online survey also revealed the ranking of the measures. With the ranked measures and the digitalization potential that arises per phase of the VCC process, the companies in the metal case have developed an implementation plan for joint IT support. Due to the shorter runtime of the metal case, not all measures were started in the implementation phase and none were completely finished. Started were the installation of an internal messenger, negotiations with suppliers regarding the calculation tool and the implementation of the login area for orders and delivery overviews as well as the implementation of a centralized knowledge base in the network.

\section{Discussion}

The metal case study was conducted as a methodological replication of the textile case study [19, 25-27]. Both studies focus on the question of how the network VCC can be improved through the use of digital technologies. By replicating the textile case in the 
new context of the metal industry, it was possible to show that the results were independent of the industry, i.e. a transfer from the technical textile industry to the metal processing industry was possible. Some context variables were deliberately retained, firstly that it is a process industry, so no discrete goods are produced, that an engineer-to-order approach is followed, so new developments are carried out according to customer orders, and both cases are SME networks serving a B2B market. These contextual variables lead to the fact that the studied networks rely on strong information and knowledge exchange in their shared value creation in order to satisfy customer needs, since there is a low degree of product standardization. Even though both are SME networks, there is a range in company sizes; while the first network with one company with over 200 employees and several 10-30 employee companies represents small to medium sized companies, the second network with the largest companies with 20 employees and the smallest company with 3.5 employees represents small companies and micro companies. Both networks feature partners with over 100 years of history, but also younger companies with less than 30 years of operating history. Thus, both networks include companies that went through far-reaching disruptions during wartime and in the history of Eastern Germany, but also companies that were founded in the reunified Germany leading to different company traditions.

The original study developed a method to support the introduction of new digital technologies and evaluated four propositions that had a positive impact on the VCC in the network. The method was transferable and the proposition could be supported again. By validating the results, the research question can be answered in such a way that the VCC in these SME networks can be improved by cross-partner planning and steering the technology introduction on the network level (method) considering the four propositions.

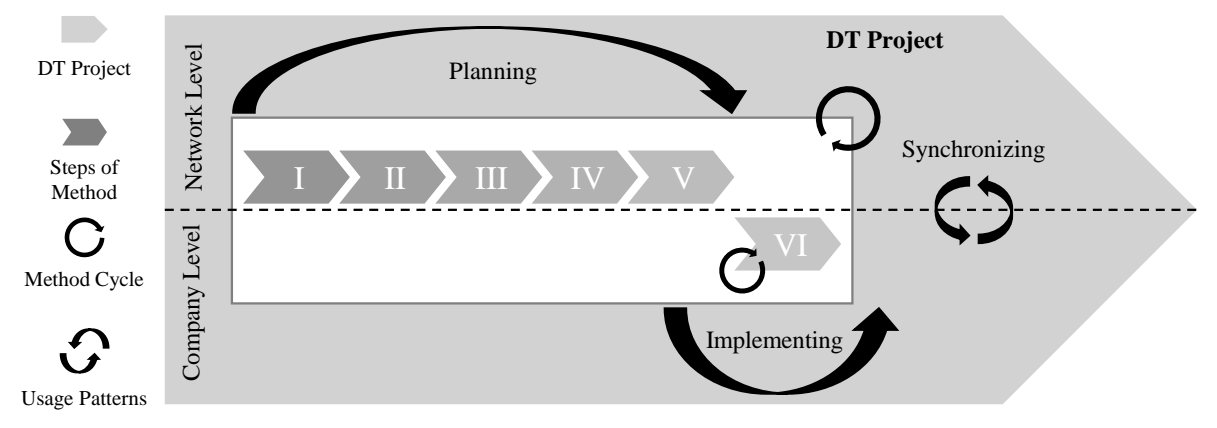

Figure 3. Depiction of the method

Although the main points of the study were confirmed, there are some deviations of the results which are shown in the following tables. The method was developed in the textile case. The steps and their sequence were defined as well as a hierarchical breakdown of the digitalization initiatives (total DT project, method cycles, and individual IT implementations). Additionally, usage patterns were found: IT planning at network level, implementation in the own company, and synchronization of the network VCC (see Figure 3). In the metal case, the method was transferred. The steps 
could be retained, but the sequence was varied e.g. by switching planning steps (in Figure $3 \mathrm{I}-\mathrm{V}$ ) or by jumping back in the step sequence. The hierarchical breakdown was seen as an important aid to structuring the DT project. The usage pattern was again observed in this way, but one company from the company level was the active leader on the network level. The implication is that the original method could be adapted with some changes, as a kind of evolution. On the one hand, the sequence of steps was made more flexible and new role constellations were considered in the use of the method.

Table 1. Comparison - (P1) internal modular VC processes with clear interfaces

\begin{tabular}{l|l}
\hline & $\begin{array}{l}\text { It could be observed, that the companies in the textile case are aware of the } \\
\text { necessity of process modularity and practice it to configure their VCC. In fact, } \\
\text { their value creation is even dependent on frequent recombination and therefore } \\
\text { a wide variety of modularization concepts have become established in the } \\
\text { network. However, the standardization using interfaces is lacking, which } \\
\text { occasionally results in coordination problems and higher complexity due to } \\
\text { frequent iterations in the process. }\end{array}$ \\
\hline $\begin{array}{l}\text { It could be observed that modularity in the value creation process is } \\
\text { recognizable and modules could be clearly identified by the companies when } \\
\text { modelling the process. In contrast, the interfaces were only considered in the } \\
\text { course of the case study and newly defined. Transfers between process sections } \\
\text { were previously unstructured and ad-hoc. The step of interface definition was } \\
\text { identified as an important step forward in the cooperation between the } \\
\text { companies. }\end{array}$ \\
\hline
\end{tabular}

This means that in both cases the internal modularity of the value creation process for cross-network configuration of the VCCs can already be observed (cf. Table 1). In both cases the interfaces are insufficient, one time too little standardized and digitalized and another time almost undefined. In both cases, however, it has also been shown that the companies have recognized great potential for improvement through the standardization and digitalization of the interfaces. The proposition (P1), which demands modularity and interfaces was confirmed, it partly supports the VCC building block transparency. Innovation through recombination of internal and external resources in the form of service modules with defined interfaces in a service system is also discussed in other studies as a new approach to VCC [40]. The modularization of services enables their mobilization in the network and thus creates transparency about which resources are available in the network [41].

Table 2. Comparison - (P2) equalization of the actors in the network

\begin{tabular}{l|l} 
In the beginning, the concern about the oversharing of sensitive information \\
dominated, which was drastically reduced in the course of the case study. The \\
lack of awareness for the necessary digitalization of inter-actor communication \\
became a hindering factor for the VCC. Despite the partnership philosophy in \\
the direct network environment, co-production plays an important role and \\
companies tend to fall into conservative stakeholder classifications.
\end{tabular}




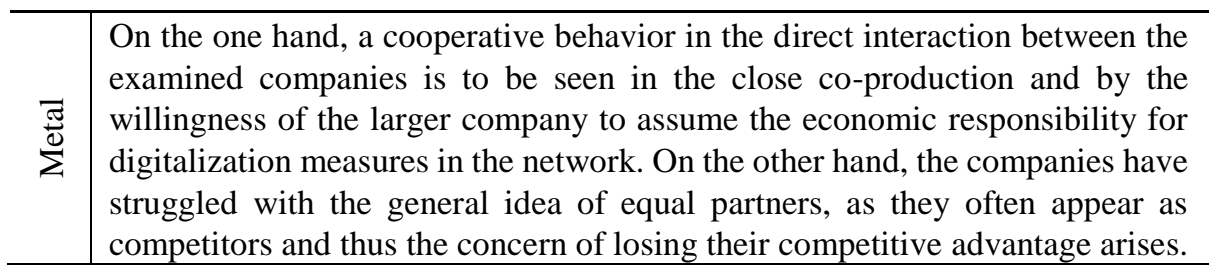

The claim of the second proposition was supported by the observations in the face-toface interaction of actors in both cases, but not when considering digital communication or documentation, where legacy processes are in place (cf. Table 2). In addition, it was observed in both cases that at the beginning the standardized sharing of internal information was perceived as a danger of over sharing sensitive information. In the long-lasting case, this phase was almost completely overcome after two years by exploring technical possibilities and intensive cooperation in the companies' digitalization project. In the shorter case, where only four months were spent working on a joint digitalization project, this learning process could only begin. The building block dialogue is supported above all by the second proposition, where equal partners act together as problem solvers $[32,33]$. Although the partnership approach between the companies has a positive effect on their VCC and this is also said by the companies themselves, the cases, which were considered in varying lengths of time, made it clear that the SMEs first have to learn certain skills for the successful use of new digital technologies in a prosperous VCC [42]. This supports the fact that SMEs in networks have to build up relational skills such as human or cultural relational capabilities [5]. This learning process then takes place again in the context of digital technologies, for example with platform capabilities, where relational capabilities have to be learned in a new environment $[1,7]$.

Table 3. Comparison - (P3) efficient and standardized communication between actors

\begin{tabular}{l|l}
\hline & $\begin{array}{l}\text { The previous predominant logic in the textile network has led to companies } \\
\text { only optimizing their own information flows and thus neglecting the }\end{array}$ \\
integration of other actors. A lot of critical information only exists in the minds \\
of individual employees such as the information "which actor can perform \\
which service". In addition, the answer to the question "Which process step \\
adds which functions to the textile" is only known by each supplier in his field \\
of expertise.
\end{tabular}

The third proposition could not be confirmed due to an absence of an efficient information flow in the two cases (cf. Table 3). However, the companies in both cases stated that insufficient information flow poses their collective biggest challenge and thus indirectly support the proposition and they identify knowledge bases and mutual access to them as prerequisites for their network VCC. Therefore, the focus was placed 
on various digitalization initiatives to improve the communication between the partners as well as to the customers. Both networks initially experienced problems with the efficient information and knowledge flow from the third proposition. This information asymmetry negatively influences both the building block transparency and the risk assessment of the VCCs [32]. However, due to the longer case study duration in the textile case, the VCC could be improved by increasing the digitalization of information and knowledge flows through the introduction and use of a shared IT platform [26]. In the metal case, concrete measures to improve these flows, such as the introduction of a messenger, are being implemented. It has been shown that efficient sharing of information and knowledge is a key element of the VCC and by disclosing critical information not only transparency is increased, but if, for example, feasibility can be assessed at an early stage, the risk of losses for the actors involved is also reduced [33].

A cross-organizational IT support could not be observed in both cases (cf. Table 4). Therefore, the fourth proposition could not be confirmed by an existing IT solution, instead, the companies described a joint IT solution along the VCC process as their envisioned approach to facilitate the VCC. Access as the last building block of the VCC was also not supported at the beginning of the two case studies, but could be realized in the textile case through the successful implementation of a shared IT platform for partners and customers with a common knowledge base. Meanwhile, in the metal case, an orchestration of several small IT solutions and joining an existing bidder platform as cross-organizational IT support was initiated to improve the VCC.

Table 4. Comparison - (P4) Cross-organizational IT support for VCC

\begin{tabular}{l|l}
\hline & The companies in the textile case are facing varying challenges with different \\
grades of digitalization and standardization in their internal processes. The \\
internal IT infrastructure of the companies already forms an important basis \\
for cross-company IT support, but obstacles in the IT of individual companies \\
can also transfer to the network.
\end{tabular}

IT infrastructures form the basis for the digital value creation strategies in which a large number of actors are connected [43]. In the two cases under consideration, two contrasting strategies for the realization of cross-organizational IT support can be recognized. In the textile case an IT platform was newly developed, which is then jointly owned and operated, corresponding to a digital manifestation of a strategic alliance as it can also be found in the newspaper industry [44]. In contrast to this, in the metal case, the aim was to use digital solutions available on the market and to join an existing marketplace platform operated by an intermediary, as often the case with SMEs due to limited resources [1].

Subsequent to this promising replication study in another industry, initial steps were taken to conduct a more extensive replication with more variation in context variables. To this end a case comparison of the textile case and a case in the Australian 
construction industry was conducted. It became apparent that there was a significant overlap of findings even though the Australian case was a B2B retailer network and the company in question, with over 300 employees, is no longer considered an SME. These insights were used as an impetus to aim for yet another replication study as further research, where again in Germany an SME retailer network in the textile industry was chosen, where the collaboration is accompanied by a clothing manufacturer and its retail stores with a digitalization project. This changes many of the context variables, it is no longer engineer-to-order, it is not a process industry, and the retailers are already operating in a $\mathrm{B} 2 \mathrm{C}$ market.

\section{Conclusion}

In our replication study we were able to confirm the findings of the original study. The implications for research are that the developed method and propositions were validated beyond the previous context. Furthermore, the studies address calls for research in the context of the VCC in networks [21]. As an implication for practice, the method for digital transformation and propositions for the improvement of VCC can be used by SME's across industries. As a limitation, we have merely carried out a methodological replication and additionally transferred it to a very similar context. Therefore, as future research we are working on a replication in a network of SME's in the retail sector.

\section{$7 \quad$ Acknowledgements}

The research described in this paper was supported by a grant from the German Ministry for Research and Education (BMBF), project name: PROFUND grant number: 03ZZ0618C.

\section{References}

1. Li, L., Su, F., Zhang, W., Mao, J.Y.: Digital transformation by SME entrepreneurs: A capability perspective. Inf. Syst. J. 28, 1129-1157 (2018).

2. Mahmood, K., Lanz, M., Toivonen, V., Otto, T.: A Performance Evaluation Concept for Production Systems in an SME Network. Procedia CIRP. 72, 603-608 (2018).

3. Goerzig, D., Bauernhansl, T.: Enterprise architectures for the digital transformation in small and medium-sized enterprises. Procedia CIRP. 67, 540-545 (2018).

4. Barann, B., Hermann, A., Cordes, A.-K., Chasin, F., Becker, J.: Supporting Digital Transformation in Small and Medium-sized Enterprises: A Procedure Model Involving Publicly Funded Support Units. In: 52nd Hawaii International Conference on System Sciences. pp. 4977-4986. Maui (2019).

5. Ngugi, I.K., Johnsen, R.E., Erdélyi, P.: Relational capabilities for value co-creation and innovation in SMEs. J. Small Bus. Enterp. Dev. 17, 260-278 (2010).

6. Stojanova, T., Suzic, N., Orcik, A.: Implementation of Mass Customization Tools in Small and Medium Enterprises. Int. J. Ind. Eng. Manag. 3, 253-260 (2012). 
7. Cenamor, J., Parida, V., Wincent, J.: How entrepreneurial SMEs compete through digital platforms: The roles of digital platform capability, network capability, and ambidexterity. J. Bus. Res. 100, 196-206 (2019).

8. Vial, G.: Understanding digital transformation: A review and a research agenda. J. Strateg. Inf. Syst. 28, 118-144 (2019).

9. Kane, G.C., Palmer, D., Phillips, A.N., Kiron, D., Buckley, N.: Strategy, not technology, drives digital transformation, https://sloanreview.mit.edu/projects /strategy-drives-digitaltransformation/, last accessed 2019/05/01.

10.Matt, C., Hess, T., Benlian, A.: Digital Transformation Strategies. Bus. Inf. Syst. Eng. 57, 339-343 (2015).

11.Singh, A., Hess, T.: How Chief Digital Officers Promote the Digital Transformation of their Companies. MIS Q. Exec. 16, 1-17 (2017).

12.Bharadwaj, A., El Sawy, O.A., Pavlou, P.A., Venkatraman, N.: Digital business strategy: Toward a next generation of insights. MIS Q. 37, 471-482 (2013).

13.Wang, Y.C.W., Chang, C.-W., Heng, M.: The levels of information technology adoption, business network, and a strategic position model for evaluating supply chain integration. J. Electron. Commer. Res. 5, 85-98 (2004).

14.Rogers, D.L.: The digital transformation playbook: Rethink your business for the digital age. Columbia University Press, New York (2016).

15.Pagani, M.: Digital Business Strategy and Value Creation: Framing the Dynamic Cycle of Control Points. MIS Q. 37, 617-632 (2013).

16.Breidbach, C.F., Maglio, P.P.: Technology-enabled value co-creation: An empirical analysis of actors, resources, and practices. Ind. Mark. Manag. 56, 73-85 (2016).

17.Muller, P., Robin, N., Jessie, W., Schroder, J., Braun, H., Becker, L.S., Farrenkopf, J., Ruiz, A., Caboz, S., Ivanova, M., Lange, A., Lonkeu, O.K., Mühlschlegel, T.S., Pedersen, B., Privitera, M., Bormans, J., Bogen, E., Cooney, T.: Annual Report on European SMEs 2018/2019 Research \& Development and Innovation by SMEs. Brussels (2019).

18.Bundesministerium für Wirtschaft und Energie (BMWi): Monitoring-Report Wirtschaft Digital 2018. München (2018).

19.Hönigsberg, S., Dinter, B.: Toward a method to foster the digital transformation in SME networks. In: 40th International Conference on Information Systems. pp. 1-8. Munich (2019).

20.De Reuver, M., Sørensen, C., Basole, R.C.: The digital platform: a research agenda. J. Inf. Technol. 33, 124-135 (2018).

21.Lusch, R.F., Nambisan, S.: Service Innovation: A Service-Dominant Logic Perspective. MIS Q. 39, 155-175 (2015).

22.Jaakkola, E., Hakanen, T.: Value co-creation in solution networks. Ind. Mark. Manag. 42, 47-58 (2013).

23.Halinen, A., Törnroos, J.-A.: Using case methods in the study of contemporary business networks. J. Bus. Res. 58, 1285-1297 (2005).

24.Dennis, A., Valacich, J.: A Replication Manifesto. AIS Trans. Replication Res. 1, 1-4 (2014).

25.Hönigsberg, S., Dinter, B.: Network Value Co-Creation Goes Digital - a Case Study. In: 25th Americas Conference on Information Systems. pp. 1-10. Cancun (2019).

26.Hönigsberg, S., Dinter, B., Wache, H.: The Impact of Digital Technology on Network Value Co-creation. In: 53rd Hawaii International Conference on System Sciences. pp. 5233-5242. Maui (2020). 
27.Hönigsberg, S.: A Platform for Value Co-Creation in SME Networks. In: 15th International Conference on Design Science Research in Information Systems and Technology. Kristiansand (2020).

28.Legner, C., Eymann, T., Hess, T., Matt, C., Böhmann, T., Drews, P., Mädche, A., Urbach, N., Ahlemann, F.: Digitalization: Opportunity and Challenge for the Business and Information Systems Engineering Community. Bus. Inf. Syst. Eng. 59, 301-308 (2017).

29.Gimpel, H., Hosseini, S., Huber, R.X.R., Probst, L., Röglinger, M., Faisst, U.: Structuring Digital Transformation: A Framework of Action Fields and its Application at ZEISS. J. Inf. Technol. Theory Appl. 19, 31-54 (2018).

30.Wessel, L., Baiyere, A., Ologeanu-Taddei, R., Cha, J., Blegind-Jensen, T.: Unpacking the Difference between Digital Transformation and IT-enabled Organizational Transformation. J. Assoc. Inf. Syst. forthcomin, (2020).

31.Teece, D.J.: Business models and dynamic capabilities. Long Range Plann. 51, 40-49 (2018).

32.Prahalad, C.K., Ramaswamy, V.: Co-Creation Experiences: The Next Practice in Value Creation. J. Interact. Mark. 18, 5-14 (2004).

33.Aarikka-Stenroos, L., Jaakkola, E.: Value co-creation in knowledge intensive business services: a dyadic perspective on the joint problem solving process. Ind. Mark. Manag. 41, 15-26 (2012).

34.Hicks, C., McGovern, T., Earl, C.F.: Supply chain management: A strategic issue in engineer to order manufacturing. Int. J. Prod. Econ. 65, 179-190 (2000).

35.Glaser, B.G., Strauss, A.L.: The Discovery of Grounded Theory Strategies for Qualitative Research. AldineTransaction, New Brunswick (1967).

36.Niederman, F., March, S.: Reflections on Replications. AIS Trans. Replication Res. 1, 1$16(2015)$

37.Yin, R.K.: Case Study Research and Applications: Design and Methods. SAGE Publications, Inc., Los Angeles (2018).

38.Mayring, P.: Qualitative Content Analysis. In: Flick, U., Kardoff, E. von, and Steinke, I. (eds.) A Companion to Qualitative Research. pp. 266-270. SAGE Publications, Inc., London (2004).

39.Baiyere, A., Salmela, H., Tapanainen, T.: Digital transformation and the new logics of business process management. Eur. J. Inf. Syst. 1-22 (2020).

40.Beverungen, D., Lüttenberg, H., Wolf, V.: Recombinant Service Systems Engineering. Bus. Inf. Syst. Eng. 60, 377-391 (2018).

41.Blaschke, M., Riss, U., Haki, K., Aier, S.: Design principles for digital value co-creation networks: a service-dominant logic perspective. Electron. Mark. 29, 443-472 (2019).

42.Eze, S.C., Chinedu-Eze, V.C.: Examining information and communication technology (ICT) adoption in SMEs - A dynamic capabilities approach. J. Enterp. Inf. Manag. 31, 338-356 (2018).

43.Tan, B., Pan, S.L., Lu, X., Huang, L.: The role of is capabilities in the development of multi-sided platforms: The digital ecosystem strategy of alibaba.com. J. Assoc. Inf. Syst. 16, 248-280 (2015).

44.Kazan, E., Ghanbari, H., Tuunanen, T., Li, M., Tumbas, S.: Strategic Design Towards Platform Collaboration in The Newspaper Industry: A Design Science Research Study. In: 53rd Hawaii International Conference on System Sciences. pp. 5086-5095. Maui (2020). 